\section{Ice flow and applied mathematics}

\section{Charles F. Raymond}

Theoretical Glaciology.

By Kolumban Hutter.

Reidel/MTP Press: 1983. Pp.510.

Dfl. 240, \$104, £60.95.

THE modern phase of glaciology opened in the late 1940s when a small contingent of physicists became interested in the motion of glaciers and ice sheets. Typical of physicists, they emphasized a research method which isolates characteristic parts of glacier behaviour to illuminate essential physical relationships, and they initiated a progressive growth in understanding that continues today. In the past few years a group with a strong applied mathematical bent has come upon the scene. These scientists like to state problems in their fullest mathematical generality, simplifying them only to the extent needed to make a solution feasible. They bring a new analytical expertise to glaciology.

Although the physical and the applied mathematical approaches are essential complements to one another, in the current glaciological community there is something of a communication gap between people who identify with one or the other. Kolumban Hutter is identified firmly with the applied mathematical viewpoint and through this book advocates it. However, Hutter also recognizes the communication gap and tries to bridge it. He has succeeded in writing a unique and rich synthesis that will please any glaciologist who makes the effort to delve into it.

In broad plan the book proceeds from a brief development of general concepts of continuum physics (Part I), to their application to specific problems in the flow of glaciers and ice sheets (Part II). Along the way there is a narrowing of complexity in the physics and a step-by-step broadening of complexity in geometry and time dependence of boundary conditions.

Part I (about one quarter of the book) covers balance laws for mass, momentum, energy and entropy, the continuity (or jump) conditions for these quantities at boundaries, and constraints on the form of constitutive relations. These principles provide the rigorous framework for describing realistic mechanical and thermodynamic behaviour of both polar

\section{New in paperback}

- The Myths of Human Evolution by Niles Eldredge and Ian Tattersall. Publisher is Columbia University Press, price is $\$ 10.95$ (in the United States and elsewhere). For review see Nature 303, 90; 1983.

- Microman: Living and Growing with Computers by Gordon Pask and Susan Curran. Published by Century, London, price $£ 4.95$. For review see Nature 302, 771; 1983. (sub-freezing) and temperate (wet) ice.

Part II deals with ice motion in geometries of increasing complexity, starting with a parallel-sided slab and progressing to three-dimensional problems. In addition, the problem of determining the geometry of the free upper surface under steady or time-varying climate is examined. While these topics have been considered in earlier books and review articles, Hutter's development is dramatically different and more expansive. Although a number of mathematical techniques are employed, perturbation expansions are a recurring theme. These analyses impressively demonstrate how far one can proceed with analytical methods, despite non-linearity of ice creep, a basal sliding law, and coupled mass and heat flow.

In the second part in particular, Hutter writes with clarity and confidence. Each chapter is crafted to stand independently yet fit into the whole. The balance of text and equations enables a reader to follow

\section{Taxonomy of vision}

David J. Tolhurst

Parallel Processing in the Visual System: The Classification of Retinal

Ganglion Cells and its Impact on the Neurobiology of Vision.

By Jonathan Stone.

Plenum: 1983. Pp.438. \$55, £42.35.

THE mammalian retina contains several populations of ganglion cells. Each population extracts information about different aspects of the visual world and conveys that information differentially to the brain. The notion of parallel processing of visual information has become so pervasive that anatomists, physiologists and psychophysicists are increasingly tempted to explain any observation in such terms. There is now a large mass of data which needs critical examination, partly to distinguish the real from the spurious and partly to resolve the many discrepancies.

It is disappointing, therefore, that Jonathan Stone has not chosen to provide a straightforward review of that published data. Rather, he uses the literature as a vehicle for expressing his views that the classification of ganglion cells is in itself the primary goal and that the central processing of visual information can be understood only in terms of parallel processing. There is no systematic description of the several populations of ganglion cell, and the references to the literature are often so cryptic that arguments cannot be followed unless the reader has a good knowledge of what has been written on the subject. It is unclear why some observations are discussed at length whilst others are ignored. The book, then, is not an introduction to the subject.

Stone's first objective is to classify gang- the thread of the mathematical development without necessarily studying all of the manipulative details.

Theoretical Glaciology does not attempt to provide much information about real glaciers or ice sheets. It also does not cover the physics of glacier sliding or water motion through glaciers, which are topics of great importance and considerable research activity. By itself, then, it is not suitable as a text for a general course in glaciology. However, for a graduate-level theoretical course in glacier dynamics it is excellent, and any glaciologist working in glacier dynamics will find access to the book to be essential. Although it remains to be seen whether Theoretical Glaciology will open a new era of glaciological research, it will undoubtedly set a new standard for mathematical analysis of ice flow.

Charles F. Raymond is Professor of Geophysics at the University of Washington, Seattle.

lion cells. He argues with some merit that the taxa should be based on an assessment of the cells' overall behaviour rather than on one "key" feature of behaviour. However, he does not explain how one should classify a cell when individual aspects of its behaviour seem to conflict. The first climax of the book is the proposal that $\mathrm{X}$ and $\mathrm{Y}$ cell classes are not at the same taxonomic level as the $\mathrm{W}$ cell class. Rather, $\mathrm{X}$ and $\mathrm{Y}$ cells are subclasses of a single XY class. The questions of why there are two kinds of cell and why their behaviour differs in particular ways is hardly considered.

The notion of parallel processing has certainly had an impact on the neurobiology of vision: there are many papers that mention it. However, Stone does not make clear how visual science would have floundered without the invocation of $\mathrm{X}, \mathrm{Y}$ and $\mathrm{W}$ cells. The central processing of visual information is described very firmly from the contention that there must be parallel processing of the information conveyed by $\mathrm{X}, \mathrm{Y}$ and $\mathrm{W}$ cells. Deviations from the theme are dismissed. For instance, the $\mathrm{X} / \mathrm{Y} / \mathrm{W}$ classification is orthogonal to Hubel and Wiesel's classification of simple and complex cells in the visual cortex. Stone implies that the simple/complex classification must, therefore, be unsatisfactory and concludes: "the question of the organization of the visual cortex to process the activities of different groups of ganglion cells is being successfully pursued without employing the 'simple'/'complex' distinction among cortical cells".

Perhaps Stone's use of quotation marks in describing simple and complex cells reveals the degree of objectivity in his discussion of parallel processing in the visual system. This is a book for the converted.

David J. Tolhurst is at the Physiological Laboratory, University of Cambridge. 